\title{
La Alemania nazi y el fascismo español durante la Guerra Civil
}

Joan Maria Thomàs

Universidad Rovira i Virgili, España.

Fecha de recepción: 23 de marzo de 2020. Fecha de aceptación: 8 de junio de 2020.

\section{Resumen}

El presente artículo reflexiona sobre las relaciones establecidas por la Alemania nazi durante la Guerra Civil española primero con el partido fascista español Falange Española de las JONS y posteriormente, desde el momento de su creación, con el partido único del régimen franquista, Falange Española Tradicionalista y de las JONS. Analiza los orígenes y desarrollo de dichas relaciones, centrándose en las de tipo político del Estado y del partido nazis establecidas por el Encargado de Negocios y después embajador general Faupel, caracterizadas por un extremado intervencionismo, así como las de su sucesor, el diplomático profesional von Stohrer, caracterizadas por una actitud más distanciada. El artículo incluye igualmente un análisis de las relaciones económicas, militares y policiales entre el régimen nazi y el Estado franquista durante la contienda.

Palabras clave: fascismo, falangismo, Guerra Civil española, Alemania nazi, partido nazi.

\section{Nazi Germany and Spanish fascism during Civil War}

\author{
Abstract \\ This article reflects on the relations established by Nazi Germany during the \\ Spanish Civil War, first with the Spanish fascist party Falange Española de
}


las JONS and later, from the moment of its creation, with the single party of the Franco regime, Falange Española Tradicionalista y of the JONS. It analyzes the origins and development of these relations, focusing on those of the political type of the State and the Nazi party established by the Chargé d'affaires and later Ambassador General Faupel, characterized by extreme interventionism, as well as those of his successor, the professional diplomat von Stohrer, characterized by a more detached attitude. The article also includes an analysis of the economic, military and police relations between the Nazi regime and the Francoist state during the war.

Keywords: fascism, falangism, spanish civil war, nazi party, nazi Germany.

\section{Introducción}

El presente texto no aborda la cuestión de las relaciones de la Alemania nazi con la llamada Zona Nacional, o España Nacional, durante la Guerra Civil española, sino otra más específica, su relación con el fascismo español durante esa misma contienda. Las relaciones generales entre los dos Estados -uno de ellos, el franquista, en primera construcción durante la guerra- han sido tratadas por la historiografía con detenimiento (Merkes, 1961; Viñas, 1977, 1984; Whealey, 1989; García Pérez, 1995; Payne, 2008), lo que no significa por supuesto que estén historiográficamente completadas. Por su parte, las relaciones específicas con los fascistas españoles lo han sido menos, aunque con valiosos trabajos recientes (Ruhl, 1986; Bowen, 2000; Morant, 2013a; Bernecker, 2002; Nuñez Seixas, 2015; Janué, 2004). Pero, ¿̇a qué nos referimos cuando hablamos de fascismo español?

\section{El fascismo español durante la Guerra Civil}

$\mathrm{Al}$ referirnos a fascismo español lo hacemos a dos organizaciones diferentes. En primer lugar al partido fascista Falange Española de las JONS, que existió entre 1934 y el 19 de abril de 1937; y en segundo, al partido único del régimen franquista, Falange Española Tradicionalista y de las JONS, creado el último día citado y subsistente durante toda la vigencia del Franquismo -ni más ni menos que hasta abril de 1977, aunque en 1958 trocó su denominación por la de Movimiento Nacional. Existieron así dos organizaciones fascistas diferentes, aunque la segunda nació en parte de la primera y la integró. La Falange-partido único incorporó de la originaria no sólo una denominación muy parecida, sino la casi totalidad de su 
programa -26 de los 27 Puntos de FE de las JONS- y una estructura interna en buena parte calcada.

Sin embargo y junto a estas similitudes, FE y FET mantenían importantísimas diferencias. FE de las JONS había sido fundada en tanto que milicia y había sido dirigida hasta el inicio de la guerra por políticos fascistas como José Antonio Primo de Rivera, Julio Ruiz de Alda, Onésimo Redondo, Rafael Sánchez Mazas y otros. Tenía como objetivos destruir la democracia, a las organizaciones de izquierdas -fuesen burguesas u obreras- y al gobierno del Frente Popular, todo ello para instaurar un régimen totalitario fascista en el que el partido hegemonizase el Estado (Sobre el concepto de fascismo vid. Payne, 1995; Paxton, 1995; Griffin, 1991; Saz, 1996, Thomàs, 2001) y su líder -Primo, que se hacía llamar José Antonio- se convirtiese en dictador (Thomàs, 2017/2019). Por su parte FET y de las JONS había sido creado como partido único no por un político fascista sino por un general en uso de sus poderes dictatoriales que, por decreto, se había auto arrogado la máxima jefatura de tal partido con el título de Jefe Nacional. Era un partido nuevo, creado a partir de la incautación de FE de las JONS y su unificación con una fuerza completamente diferente, no fascista, la Comunión Tradicionalista de los carlistas, monárquica neoabsolutista y ultracatólica (Thomàs, 2001).

Es decir, que ni Franco era un líder fascista ni había llegado al poder en tanto que líder de una fuerza de este tipo, sino como un dictador militar interesado en dotar a su naciente Estado de una base de masas fiel y subordinada a su persona y, eso sí, creada a imagen y semejanza de las de los dos principales aliados, la Alemania nazi y la Italia fascista. Pero a diferencia de aquellos países, no estaba dispuesto a que en España ese partido único de tipo fascista tuviese en sus manos los resortes fundamentales del poder del gobierno y del Estado. Ni tampoco a aplicar de manera primordial el programa fascista de la anterior Falange.

Bien al contrario, tenía bajo su mando una coalición autoritaria ideológicamente diversa, nacida con la guerra y formada por instituciones como la iglesia católica y el ejército; por los fascistas falangistas, ahora unificados en FET; por los carlistas, también unificados; por los monárquicos alfonsinos autoritarios; por exdirigentes y ex miembros corporativistas católicos desengañados de Acción Popular/CEDA; por grandes propietarios e industriales; y por decenas de miles de medios y pequeños campesinos, sectores de clases medias y medias bajas urbanas, y aún de clases trabajadoras, todos ellos católicos. Y no todos fascistas, por lo que el llamado Caudillo no estaba dispuesto a conceder a éstos la hegemonía política, sino a repartir cuotas de poder entre los componentes de la coalición. Cuotas 
de poder variables y siempre a partir de la subordinación absoluta a su mando (Thomàs, 2016).

Al nuevo partido único, para la dirección del cual promocionó -de la mano de su principal consejero político de los años 1937 a 1941, y concuñado, Serrano Suñer, que ocuparía tras la Guerra Civil y durante tres años su lugartenencia- a exdirigentes de FE de las JONS, estaba dispuesto a asignarle poderes nada despreciables, como el monopolio de la construcción y dirección de una organización sindical vertical que disciplinase y encuadrase a las clases trabajadoras -mientras reprimía brutalmente a los sindicatos de izquierdas, puestos fuera de la ley desde la primera semana de la guerra-; el encuadramiento de sectores de la población en la organización; un papel fundamental en la socialización política de las mujeres y de la juventud, incluida la universitaria; y una parte nada despreciable del control de los aparatos de prensa y propaganda de la Zona Nacional. Todo ello en paralelo al propio desarrollo del gran aparato político y burocrático del partido.

Ello no obstante, el décalage existente entre las aspiraciones de una parte de los dirigentes falangistas viejos y la realidad del nuevo partido conllevaría en los años siguientes serias fricciones, manifestadas ya en el momento mismo de la creación de FET y de las JONS y que culminarían finalmente, en la postguerra, en la Crisis de Mayo de 1941. Tras ella, los dirigentes falangistas aceptarían su papel dentro de la coalición -que, como acabamos de ver, no era poco relevante- y dejarían de presionar para obtener la hegemonía. Aceptarían esperar una "orden de marcha" en el cumplimiento de sus aspiraciones por parte de su Jefe Nacional Franco que nunca llegaría (Thomàs, 2016).

Pero ¿Por qué habían optado Franco y sus consejeros por crear un partido único de tipo fascista, parecido a los nazi y fascista italiano? Y ¿Por qué se habían inclinado por la primacía del programa, estructuración y aún estilo de los falangistas a la hora de configurar ese mismo partido? Creemos que por la primacía incontestable de FE de las JONS sobre la Comunión Tradicionalista dentro de la Zona Nacional durante los primeros nueve meses de la guerra, siendo la fuerza más numerosa; por la aparente mímesis tal adopción podía significar respecto de los regímenes políticos fascistas de sus dos principales aliados -que no fueron, por otra parte, ajenos en sus recomendaciones por la opción tomada-; y por el ideario "moderno" que el de los falangistas fascistas significaba respecto del tradicionalista carlista, con las referencias a la justicia social y regeneración patria que contenía y que el propio Franco podía ver con simpatía en algunos aspectos, aunque fuese consciente de la complejidad de sus apoyos y de la necesidad de mantener la cohesión de la coalición. 


\section{2. ¿Qué política adoptó el régimen nazi hacia el bando llamado "nacional" durante la Guerra Civil?}

Contrariamente a la versión conspirativa que circuló profusamente por la Zona Republicana durante la guerra -y cuyos ecos llegaron hasta mucho más tarde-, ni Hitler ni la Alemania nazi estuvieron detrás del golpe de estado militar del 18 de Julio de 1936 (Bernecker, 2002: 160-161). Por supuesto tampoco "Rusia" había estaba preparando una revolución comunista en España, como se argumentaría durante decenios en el otro bando. Algo que los nazis sabían perfectamente y que tenía que ver no ya con la propia debilidad de los comunistas españoles sino con la política antirrevolucionaria de los mismos y de Stalin -aspirante al apoyo de las clases medias-, lo que trajo como consecuencia el evitar todo tipo de revolución social en el campo republicano durante la guerra (Bernecker, 1982). También eso lo sabía Hitler. Otra cosa es que temiese la influencia futura que tanto la propia URSS como Francia y Gran Bretaña pudieran llegar a tener sobre una República española victoriosa tras derrotar de los militares sublevados.

Ello quedó claro en las instrucciones que le dio al general Faupel, el primer encargado de negocios que envió a la capital de facto de la Zona Nacional -Burgos- y al Cuartel General del Generalísimo -Salamanca- en noviembre de 1936. Existen varias versiones de lo dicho concretamente por el Führer, aunque todas coincidentes en el fondo. Según una de ellas, habría dicho que su misión consiste única y exclusivamente en evitar que, una vez concluida la guerra, la política exterior española resulte influida por París, Londres o Moscú, de modo que, en el enfrentamiento definitivo para una nueva estructuración de Europa -que ha de llegar, no cabe duda-, España no se encuentre del lado de los enemigos de Alemania, sino, a ser posible, de sus aliados (Viñas, 1977: 363). Así como que no debía inmiscuirse en la política interior española, especificando que el tipo de gobierno que saliese de la victoria del bando sublevado le importaba poco.

Según otra versión, habría sido más prolijo, instruyendo a Faupel en el sentido de que nuestra decisión de tomar partido por Franco corresponde en primer lugar a las necesidades de la política mundial y solamente en segundo lugar a una preferencia hacia determinadas tendencias en la política exterior española. El Frente Popular en Francia, la caída de la moneda francesa, que ha abandonado el patrón oro, y la creciente preocupación de un empeoramiento de la situación económica -todo esto abre al comunismo mundial las puertas de Francia sin lucha. Medio año de política del Frente Popular en España ha demostrado que allí la orientación hacia Moscú se lleva a cabo aún más rápidamente que en Francia. Un bloque francés-español en la frontera occidental de Alemania, orientado 
hacia Moscú, sería una horrible pesadilla, peor que la preocupación de la coalición adversa que condujo a la Primera Guerra Mundial. Si Alemania milita en lo sucesivo en el campo nacional, se quiere ahuyentar aquella pesadilla. He aquí la más importante y única tarea para el embajador alemán en Salamanca. Y en lo referente a la política interior de la Zona Nacional, habría el Führer dejado claro que lo que sucede en política interior de España constituye, comparado con esta tarea [internacional geoestratégica] un problema secundario. Que gobierne un general, un presidente, un príncipe de la iglesia, una junta de oficiales, un consejo de corporaciones o un jefe de un partido en España todas estas elecciones son aceptables para Alemania mientras garanticen que España no será tomada al remolque por Rusia ni caerá bajo la influencia del comunismo mundial. Y, más específicamente, había añadido: Busque usted en política interior los grupos con los cuales quiere colaborar, no según sus informes [¿̇sic por uniformes?], sus emblemas o el contenido de un programa altisonante. Busque sobre todo a los hombres que son de confianza en este punto fundamental y a ellos preste usted su apoyo. Haciendo esto, tanto la forma de gobierno como la constitución resultan secundarios, aunque se diferencien muchísimo de las soluciones que nos parecen las más acertadas para nuestros problemas en Alemania (Sáenz-Francés, 2009: 125).

En cuanto a Franco, eran Hitler y sus colaboradores más inmediatos conscientes de que no era en modo alguno el revolucionario fascista al que correspondía ayudar por motivos de afinidad ideológica. La considerable ayuda que Franco recibió de la iglesia católica oficial y la presentación del alzamiento como fenómeno pseudo-religioso -al calificarlo de "cruza$d a^{\prime \prime}$ - pusieron de manifiesto ya desde un comienzo las graves diferencias existentes con respecto a la doctrina nacionalsindicalista (Bernecker, 2002: 162).

Es decir, que la geoestrategia anticomunista nazi fue central, junto con la enemiga de la plutocracia francesa, en la decisión de Hitler de prestar ayuda a Franco y a los sublevados en España. Pero a estas razones se unieron, casi desde el principio, otras de tipo económico. No, en cambio, la voluntad de crear un régimen similar al nazi en España. Ni tampoco, en el momento de la decisión inicial, cuestiones relacionadas con la utilización de la guerra de España para probar armas germanas, especialmente aéreas -aunque ello se acabase haciendo, y a qué precio de vidas españolas.

En cuanto a las razones que trascendieron públicamente por parte de Alemania -las que difundió la propaganda nazi- se centraron en el anticomunismo y quedaron codificadas en el relato construido al efecto por el ministro de Educación Popular y Propaganda, Goebbels. Relato que 
explicaba la contienda de España en tanto que librada entre un bando heroico y redentor, el nacional, y "los bolcheviques". De manera similar, la propaganda oficial franquista se centró en el anticomunismo, presentando la ayuda alemana como un gesto solidario en la lucha común en la cruzada antibolchevique.

Concretando más las razones geoestratégicas de Hitler, cabe señalar que se centraron primero en lograr un aliado al sur de Francia -de la Francia con la que se preveía guerra-y después, desde finales de octubre de 1936, en responder a la ayuda soviética a la República con el envío de la Legión Cóndor. Todo ello dentro de su consideración general del área mediterránea como de influencia italiana, y así reconocérselo a Mussolini en septiembre de 1936. Al tiempo que consideraba el Este europeo y al Báltico de la competencia de Alemania. Algo que ambos reafirmaron un año más tarde (Whealey, 1989: 47-48).

En cuanto a las razones de tipo económico y financiero -que estaban también por supuesto relacionadas con la estrategia- tengamos en cuenta que, en el verano de 1936 en que estalló la Guerra Civil en España, Alemania estaba sumida en una crisis sin precedentes de falta de divisas, lo que había mermado su capacidad de adquisición de materias primas. De unas materias primas imprescindibles para continuar su política de rearme. Precisamente para tratar de solventar esta situación se había creado el llamado Plan Cuatrienal y puesto en las manos de Göring. Es decir, de alguien que se había opuesto en un primer momento a la concesión de ayuda a España cuando se la habían solicitado en entrevista personal con Hitler, en Bayreuth la noche del 25 al 26 de julio de 1936, dos enviados de Franco. En concreto dos nazis miembros del servicio exterior del NSDAP, la Ausland-Organisation (AO), del Protectorado español de Marruecos, Bernhardt y Langenheim. Pero un Göring que muy poco después se había dado cuenta de las ventajas que la relación con los sublevados españoles podía suponer económicamente para el Reich, activando inmediatamente tanto al Plan Cuatrienal como a la propia AO para tomar en sus manos la puesta en práctica de la ayuda y dejando de lado tanto al Ministerio de Asuntos Exteriores (Auswärtiges Amt) como a la propia representación diplomática alemana en Salamanca (Morant, 2013a. Agradezco al autor que me haya facilitado un ejemplar de su tesis doctoral inédita). De hecho, la guerra de España pasaría a ser conocida en círculos militares alemanes como "la guerra de Göring" (García Pérez, 1994: 57-58; 61-63).

Todo lo cual no deja de ser una muestra más de la realmente existente poliarquía nazi. Es decir, de la fragmentación del poder existente dentro del régimen, así como de la competencia interna por el mismo (o de los 
mismos) establecida entre dirigentes y organismos nazis. Que se manifestaba también en la continua creación de órganos para realizar actuaciones en lugar de aprovechar otros del aparato del Estado preexistente, o para sortear otros nuevos creados por jerarcas diferentes.

En el caso del envío de ayuda militar a España, se optó por disimularlo como negocio privado, organizando primero y ya en el mismo mes de julio de 1936 una empresa, la Sociedad Hispano-Marroquí de Transportes Ltda (HISMA), dirigida por el citado Bernhardt. Un hombre que mantenía excelentes relaciones con Franco y que por ello mismo había sido enviado por éste a Bayreuth. Bernhardt había utilizado para acceder a Hitler sus contactos dentro de la AO, en lugar de dirigirse al Ministerio de Asuntos Exteriores, lo que había resultado clave para conseguir el acceso primero y el apoyo después del Führer (Viñas, 1984). Gracias a todo ello, un Franco aún no Generalísimo ni Jefe del Estado se había convertido en el receptor -y redistribuidor entre el resto de generales sublevados- de la ayuda militar germana. Unos meses más tarde y también por orden de Göring, se había fundado otra compañía -Rohstoffe und Waren Einkaufsgesellschaft GmbH (ROWAK)- en tanto que contraparte organizadora y receptora en Alemania de los envíos de productos españoles procedentes del intercambio con los suministros militares alemanes. Las dos empresas monopolizarían este comercio, desplazando además, y por decreto, a otras empresas privadas también germanas que anteriormente venían comerciando con España. Los intercambios se realizarían con un sistema de compensación que no exigía el uso de divisas y que, de hecho, no era sino un trueque. Posteriormente, a finales de 1938, HISMA y ROWAK formarían el holding SOFINDUS (Sociedad Financiera Industrial Limitada) (Bernecker, 2002: 167-170).

Como consecuencia estos intercambios con la Alemania nazi, ésta se convirtió en el principal socio económico de la España Nacional durante la Guerra Civil, superando a Gran Bretaña, Estados Unidos y Francia. Se adquirieron en la Zona Nacional masivamente materias primas minerales, lo que fue facilitado por la toma de control por parte de la Junta de Defensa Nacional española ya en agosto de 1936 de todos los recursos minerales (decreto de 28 de agosto de 1936 (García Pérez, 1994: 61). Asimismo, Alemania adquirió derechos sobre más de un centenar de minas de hierro, piritas, cobre, plomo, wolframio, estaño, cinc, cobalto y níquel. E importó grandes cantidades de aceites, pieles, corcho, lana, cueros, vino y otros productos agrícolas y ganaderos. Todo ello no estuvo exento de problemas con las autoridades franquistas, aunque tendieran a minimizarse dada la extremada dependencia militar existente del país germano, que se aprovechó descaradamente de la situación. 
Hitos de las relaciones generales entre los dos países fueron la firma de diversos protocolos -secretos- en 1937, uno de los cuales, el de 16 de julio, abría la puerta a que una parte del pago de la deuda de guerra española pudiese cobrarlo Alemania con inversiones en sectores productivos de la península, islas y Protectorado de Marruecos, vía fundación de sociedades españolas con participación alemana -sujetas, eso sí, a las limitaciones legales españolas sobre participación extranjera en la propiedad. Las inversiones mineras alemanas se agruparon en una nueva compañía, subsidiaria de HISMA, Montaña S.A. El límite en la propiedad se fijó en el cuarenta por ciento, si bien en el otoño de 1938 y tras recibir Franco fuertes presiones germanas -que condicionaban la continuación sus suministros en unos momentos en que el ejército franquista los necesitaba, tras el desgaste que había supuesto la batalla del Ebro y para emprender la ofensiva definitiva sobre Cataluña- se acabó ampliando. Ello aparte del uso masivo por parte de Alemania de testaferros españoles en las empresas participadas.

Todo este entramado de inversiones en concesiones mineras se revelaría extremadamente útil para Alemania a partir del inicio de la Segunda Guerra Mundial, momento en el que muchos de los yacimientos comenzarían a explotarse o lo harían ahora de manera intensiva (García Pérez, 1994: 75). En otros sectores productivos primarios, también crearon empresas dedicadas a la producción agrícola y ganadera. Y las tensiones se multiplicaron con una España ultranacionalista celosa de su independencia. Tensiones que tras el fin de la guerra pasarían a focalizarse en la cuestión de la fijación del monto total de la deuda contraída por la España Nacional. Entonces Alemania conseguiría incluir en la misma, junto con el coste de los suministros proporcionados, los gastos de personal de la Legión Cóndor (García Pérez, 1994: 82).

Políticamente la Guerra Civil sirvió para el establecimiento de sólidos lazos entre los dos países -incluyendo los de tipo policial. En los protocolos secretos de 1937 se acordaron consultas permanentes en cuestiones como la lucha contra el comunismo, el compromiso de profundizar en las relaciones entre los dos Estados y recíprocas neutralidades benévolas en caso de guerras con terceros (García Pérez, 1994: 83). De hecho ya en noviembre de 1936 Franco había solicitado a Alemania ayuda para formar a la policía franquista en la lucha anticomunista, lo que motivó la llegada a la Zona Nacional de una delegación policial por un jerarca de las SS que trabajaría durante el resto de la contienda con el Ministerio de Orden Publico -creado en enero de 1938- (Whealey, 1989: 62). A nivel de relaciones exteriores, y ya de la mano del embajador von Stohrer -desde septiembre de 1937- y del ministro de Exteriores von Ribbentrop, la España Nacional se adhirió al Pacto AntiKomintern -firmado por Alemania y Japón en 1936, y por Italia 
en 1937- en marzo de 1939 y ese mismo mes firmó un Tratado de Amistad con Alemania de cinco años de vigencia. Tratado que venía a consolidar los acuerdos incluidos en los protocolos y que preveía la profundización de las relaciones militares, económicas y culturales entre los dos países. Y el 8 de mayo de 1939, la España franquista abandonó la Sociedad de Naciones, como lo habían hecho años antes Japón y Alemania -en 1933-e Italia -en 1935 .

La decisión de intervenir en España sido un éxito tanto a nivel geoestratégico como económico y financiero. Alemania tenía ahora un aliado al sur de Francia, ligado por tratados políticos y económicos, y endeudado no sólo financiera sino también políticamente. Una España que todo indicaba estaba además ansiosa por colaborar con Alemania en la construcción de un nuevo orden en Europa. Orden que debería servirle a Franco para sacar a España su dependencia de las odiadas plutocracias. Sin embargo, la España franquista era también un Nuevo Estado ultranacionalista, con sus propios intereses y sus propias aspiraciones imperiales, lo que provocaría, después del fin de la Guerra Civil y ya en plena contienda mundial, un desencuentro estratégico notable con Hitler. En medio, eso sí, de una amplia colaboración, tanto abierta como encubierta, con el régimen nazi en su lucha contra las plutocracias y, desde el 22 de junio 1941, contra el conjuntamente odiado comunismo bolchevique.

\section{3. ¿Qué política adoptó el régimen nazi hacia el fascismo español durante la Guerra Civil?}

Mientras estuvo en su cargo, es decir, hasta cuatro meses después del Decreto de Unificación de 19 de abril de 1937, el principal hombre de Alemania en la Zona Nacional, el general Faupel, se esforzó por conseguir no sólo la hegemonía política y económica para su país en España, sino porque Falange Española de las JONS tuviese un papel preponderante en la política interior de la Zona Nacional. Es decir, hizo una lectura propia y personal de las instrucciones generales recibidas del Führer en su entrevista con él y con el ministro de Exteriores de entonces, el conservador von Neurath, en noviembre de 1936.

De todas actuaciones que, en el triple campo militar, político y diplomático, tuvo primero como encargado de negocios y después -desde marzo de 1937- como embajador, trataremos seguidamente del segundo. Del tercero ya nos hemos ocupado, y del primero cabe reseñar sucintamente que se comportó respecto de Franco y del ejército como si fuesen un general y un 
ejército sudamericanos -del tipo de los que había asesorado en años anteriores en ese subcontinente. Mientras que, con respecto a sus compatriotas militares destacados en la Zona Nacional, destacaron sus choques con el responsable de la Legión Cóndor, general Sperrle. Actuando por su cuenta, pidió -sin éxito- a Hitler que se incrementase significativamente el contingente militar germano; demandó -esta vez con éxito- el envío de oficiales alemanes para entrenar a suboficiales y oficiales de las milicias de FE de las JONS; y exigió -de nuevo sin éxito- que se crease un alto mando conjunto alemán-italiano al margen de los responsables militares germanos realmente actuantes (The Chargé d'Affaires in Spain to the Foreign Minister, Salamanca, December 10, 1936, en Documents on Foreign German Policy 1918-1945, 1951: 159-162). Por supuesto, con tales iniciativas la enemiga con que contaba en la cúpula de la Wehrmacht no hizo sino aumentar. Por no hablar de la irritación que generaron en el propio Franco.

Como decimos, de entre las fuerzas políticas actuantes dentro de la Zona Nacional, optó Faupel, siendo como era nazi antes de que existiese el nazismo (Sáenz-Francés, 2009: 124), por la fascista Falange Española de las JONS y, dentro de ella, por su líder -provisional- Hedilla. Todo ello le acabaría pasando factura y se superpondría a sus logros -que no fueron pocos, especialmente las firmas de los protocolos de 1937- y acabó siendo cesado en su cargo de embajador en agosto de 1937. En general puede decirse que, en cuanto a la relación Alemania-España Nacional, probablemente no entendió que en el fondo Hitler no tenía demasiado inconveniente en ceder la preferencia a Italia en todo lo referido a implicación política y militar -la económica, como acabamos de ver, era otra cosa. Y se entrometió demasiado en la política interior. Su sucesor, el diplomático profesional von Stohrer, aprendería la lección y no se inmiscuiría en las interioridades de la coalición autoritaria franquista, aunque también trabajaría con FET y de las JONS. Es decir, con el partido único, lo que era otra cosa, precisamente por ser ya oficial y contar con Franco como su Jefe Nacional. Tampoco se entrometería en cuestiones militares y continuaría, culminándolos, los esfuerzos de su antecesor por la firma de acuerdos estables con España en forma de tratados.

Para entender la actuación de Faupel debemos tener en cuenta que en su nombramiento habían pesado por encima de todo criterios políticos y no profesionales. Había sido elegido por Hitler probablemente por recomendación de un alto cargo de la Ausland-Organisation, Köhn, próximo a tres de los más prominentes altos cargos nazis -Hess, Göring y Goebbels. Köhn conocía bien a Faupel por haberle tratado en Hispanoamérica y después en las instituciones iberoamericanistas que el general dirigía en Berlín (Morant, 2013a: 328), gracias al partido nazi -al que no perteneció 
oficialmente hasta su nombramiento en España. Nos referimos al Instituto Iberoamericano/Ibero-Amerikanisches Institut de Berlín (cuya dirección ostentaba desde 1934) y la Sociedad Germano-Española/DeutschSpanische Gesellschaft (desde febrero de 1936).

Teniente general, excombatiente en la Gran Guerra y jefe de un Freikorps en Silesia en la inmediata postguerra, en los años veinte y primeros treinta había ocupado altos cargos en dos ejércitos sudamericanos, el argentino y el peruano (Gliech, 2003: 131-279; Janué, 2013: 240-260). Mantenía igualmente muy buenas relaciones con Fritz Thyssen, el dueño de la poderosa química I.G. Farben, y otros empresarios que habían colaborado en el ascenso del régimen nazi. De hecho en el propio ejército se le conocía como el general IG (Sáenz-Francés, 2009: 124) y probablemente como un alto militar demasiado "político".

Al ser un nombramiento político, el suyo no fue bien visto por el Auswärtiges Amt. Ni tampoco, por las razones citadas, por la cúpula de la Wehrmacht. El candidato del Ministerio de Exteriores había sido el diplomático profesional von Stohrer, quién había estado a punto de ser nombrado unos días antes de la designación del general y que antes de la guerra, en julio de 1936, había estado propuesto como embajador en Madrid. Pero en favor de Faupel habían jugado los citados Goebbels, Göring y Hess -cuyo hermano era la mano derecha del jefe de la Ausland-Organisation, Bohle (Whealey, 1989: 54; Morant, 2013a: 327).

En resumen, que siendo como era un nazi convencido, no es de extrañar que el general se involucrase en la política interior de la Zona Nacional, como también lo hicieron el propio Köhn y otros de la cohorte que llevó consigo a Burgos. Es más, Köhn había sido enviado ya antes del nombramiento del general por Goebbels y Hess a Salamanca para pulsar el ambiente y en el informe que redactó mostró las intenciones políticas que, tanto él como sus valedores en Berlín, tenían para el futuro de España. Describió a Franco como gran figura, totalmente nuestro hombre. Muy político y absolutamente del lado alemán. Tanto él como todo el pueblo reconocen con profundo agradecimiento nuestra ayuda militar. Se quiere con sinceridad una España fuerte, social. Ningún peligro de recaer en la reacción. [ ] Los falangistas todavía pequeños, pero el futuro movimiento popular (Morant, 2013a: 328). Es decir, que la idea de intervenir en política interior venía de origen. Otra cosa diferente sería el tipo de intervención que acabó haciendo el Faupel, así como su extremada y ya mencionada capacidad para irritar a destacados compatriotas suyos -en España y en Alemania-, así como al propio Franco y su entorno político de Salamanca. 
Junto a Köhn -encargado de dirigir una oficina de propaganda y relaciones culturales dependiente, a través de él, de Goebbels- y que sería muy pronto nombrado cónsul general, acompañaron al general, Kröger, adscrito también a la oficina de propaganda; Stille, joven diplomático que ejercería como secretario de la legación y sería el encargado de ayudarle en los menesteres profesionales (Sáenz-Francés, 2009: 124-126); y Winzer, de la GESTAPO (Whealey, 1989: 63; Merkes, 1969: 249-250).

Faupel consideró al partido fascista español el instrumento fundamental para conseguir la implantación de un régimen fascista en España que se convirtiese en un aliado estrecho de Alemania (Merkes, 1969: 121; 249250). En este último sentido podía escribir a Exteriores en Berlín que there is no doubt that [after] a war won because of our intervention, a Spain socially ordered and economically reconstructed with our help will in the future be not only a very important source of raw materials for us, but also a faithful friend for a long time to come (The Ambassador in Spain to the Foreign Ministry, Salamanca May 1, 1937, DFGP, 1951: 277). En cuanto a los falangistas, les veía como equivalentes a los nazis en el contexto español (Nuñez Seixas, 2015: 24), por lo que trabajó con ellos, en competencia con los italianos, que también pretendían influir y atraerlos.

En función de ello conseguiría para FE de las JONS el citado envío de instructores alemanes para sus academias de jefes de centuria; se mantendría cercano a su jefe provisional Hedilla, apoyándole en su lucha por el poder interno durante los llamados Sucesos de Salamanca; suministraría al partido propaganda nazi; y organizaría viajes de jerarcas falangistas a Alemania para que vieran de cerca la realidad del régimen nacionalsocialista, antes y después de la Unificación. Y lo hizo mientras argumentaba que si algún día queremos recoger en los planos político y económico los frutos de nuestro apoyo [a Franco] debemos ponernos en marcha precisamente ahora $y$ con la mayor fuerza posible en los ámbitos cultural y social (Faupel a Auswärtiges Amt 12 de marzo de 1937 cit. en Morant, 2013b: 320).

Al poco de su llegada a la España Nacional había sido fusilado en Alicante el fundador y primer -y único- Jefe Nacional de FE de las JONS, José Antonio Primo de Rivera, en cuyos intentos de liberación habían participado el vicecónsul alemán en Alicante von Knobloch, con el apoyo de la marina de guerra, la Kriegsmarine (Viñas, 1977; Thomàs, 1999). En el lugar de Primo y en tanto que jefe provisional venía actuando en la Zona Nacional el citado Hedilla y con él estableció Faupel su conexión a través de algunos personajes clave, como Serrallach y Martín Almagro. El primero, que era su secretario privado y que al parecer había militado en el partido nazi durante su etapa de estudiante en Frankfurt sería enviado por Hedilla, con 
el apoyo de Faupel, a Berlín para recolectar propaganda y publicaciones del NSDAP. También actuaría como receptor, traductor y adaptador de las publicaciones que desde la oficina de Köhn se enviaban al partido; y en las gestiones para la organización de escuelas de jefes de centuria falangistas con instructores alemanes. De él escribiría Faupel que trabaja muy bien con nosotros (Faupel al Auswärtiges Amt 1 de febrero de 1937, R102.985 Politische Spanien. Auswärtiges Amt Archiv, en Thomàs, 2014: 39).

También apoyaría Faupel a Hedilla en su proyecto de dejar la provisionalidad de su jerarquía y convertirse en nuevo Jefe Nacional del partido en abril de 1937, frente a otros jerarcas. Un enfrentamiento que causó dos muertos y fue aprovechado por Franco para decretar la Unificación y situarse él mismo como jefe. En esta pugna interna el Generalísimo había apoyado a Hedilla al considerarlo, con razón, más proclive a la fusión que sus oponentes. De hecho, es probable que Hedilla fuese uno de los que influyesen para que el nuevo partido único se inspirase en FE de las JONS y fuese de tipo fascista. Sin embargo, cuando, una vez creado, y como resultado de las presiones recibidas de sus adversarios, se negó a aceptar el cargo para el que Franco le había nombrado en la nueva organización, tratando de negociar las condiciones de la fusión, fue detenido, procesado y condenado a muerte. Y de esta manera pasó Franco de pensar en enviarle a Alemania e Italia para que aprendiese allí aspectos de las reformas sociales nazis para aplicarlas a la reconstrucción social de España (Faupel to the Foreign Ministry May 11, 1937, DFGP, 1951: 285) a castigarlo durísimamente, al sentirse engañado por la -presunta- deslealtad del personaje.

Faupel criticaría en sus informes a Berlín la manera de proceder del Generalísimo. Se puede crear una brigada a partir de dos regimientos mediante una orden -escribiría-pero ( ) fusionar y unir dos partidos lleva algo de tiempo, incluso si, como es el caso, sus programas sociales son muy similares (Faupel a Auswärtiges Amt 28 de abril de 1937. Auswärtiges Amt Archiv. El documento está reproducido con fecha 1 de mayo de 1937 en DFGP, 1951: 277). Sin embargo, tuvo también claro desde el primer momento -y en ello coincidía con el jefe de la oficina de propaganda italiana en la España Nacional, Danzi- que no se podía apoyar ninguna resistencia a las órdenes del Caudillo (Les Archives secrètes de la Wilhemstrasse, 1952: 209-212).

Fue precisamente en relación con este asunto cuando llegó al máximo de sus intromisiones en política interna. Tras la condena a muerte de Hedilla fue a ver a Franco y le dijo, in a friendly conversation, que the shooting of Hedilla, the only real representative of the workers, will make a very bad impression and that it is dangerous to create martyrs in the present 
situation. Pero no se quedó ahí y propuso a Berlín que se le autorizase a hacer al Caudillo una declaración oficial en nombre del Gobierno del Reich en el mismo sentido. Petición que fue rechazada por el Ministerio de Exteriores inmediatamente (Faupel a Auswärtiges Amt June 9, 1937; Auswärtiges Amt to Faupel June 10, 1937 en DFGP, 1951: 312-313; 319). De la irritación que el personaje creaba en el Cuartel General del Generalísimo podrían ser prueba las invectivas que le dedica Serrano Suñer en sus memorias (Serrano Suñer, 1973; sobre Serrano vid. Gómez Molina-Thomàs, 2003).

Ahora bien, parece ser que al contrario de lo que se ha venido afirmando repetidamente, en su cese tuvieron un mayor peso las presiones militares -del jefe de la Legión Cóndor y de la cúpula de la Wehrmacht- que no el tema Hedilla. Eso es lo que se desprende del diario secreto de otro embajador alemán, éste de 1943, von Moltke, que lo recogió de conversaciones con Stille, anterior asesor diplomático de Faupel, como sabemos. Al decir de aquel, Stille fue testigo cuando Faupel se mezcló en un momento crítico, abril de 1937, en la política interior española y conoce además los detalles de la caída de Faupel en agosto de 1937, cuando el general Sperrle y el Ministerio de la Guerra torpedearon al embajador-general, que era tan impopular entre ellos (Sáenz-Francés, 2009: 126; Sáenz-Francés, 2006: 85-134)

En cuanto a los viajes a Alemania de jerarcas y militantes de FE y FET que durante 1937 organizó Faupel, cabe señalar que utilizó para hacerlo a la Sociedad Germano-Española (DSG), entre otros canales. Llevó a jóvenes falangistas a visitar las organizaciones juveniles nazis; a una delegación de Auxilio Social liderada por Carmen Werner, que estuvo unos meses estudiando las organizaciones femeninas nazis (Morant, 2013b: 317-334); a una de las máximas dirigentes de la Sección Femenina, De Icaza, y al delegado de Propaganda, Ridruejo, que hicieron un tour por el país, entrevistándose con el Führer; y a la propia responsable de Auxilio Social, Sanz Bachiller (Bowen, 2000: 38 y ss.). También, y de acuerdo con la delegación de Falange en Alemania y la jefatura de Prensa y Propaganda del partido organizaría el envío de films y propaganda nazis a la España Nacional.

Con la llegada del nuevo embajador Stohrer en septiembre de 1937, los contactos entre el partido nazi y el partido único español se incrementaron, en paralelo a como lo hacían las relaciones generales entre los dos países. Continuaron siendo importantes los trabajos, ya desde Berlín, de Faupel, vía DSG, que de hecho se multiplicaron incluyendo conferencias, recepciones, actos benéficos, exposiciones, becas e intercambios científicos (Janué, 2013: 258); y desde Salamanca de Köhn. Es más, a raíz del nombramiento 
en febrero de 1938 de Ribbentrop como ministro de Exteriores, el papel de Köhn en tanto que encargado de las relaciones propagandísticas con Alemania al frente de la oficina Sonderstab se incrementó, así como sus actividades, algo que no agradaba al diplomático profesional Stohrer (Morant, 2013a: 348-357).

Hitos destacados de las relaciones entre el partido nazi y el español en esta etapa fueron las visitas a la España Nacional de delegaciones de las juventudes hitlerianas; la de la delegada nacional femenina Primo de Rivera a Berlín en abril de 1938; y la de una delegación española al congreso anual del NSDAP en Nuremberg, entre otras (Bowen, 2000: 50). Y por supuesto con el fin de la Guerra Civil española el 1 de abril de 1939 las relaciones oficiales entre la FET y de las JONS y el NSDAP no hicieron sino incrementarse, llegándose al clímax de los años 1939-1941. Pero ésta es ya otra historia. 


\section{Q Bibliografía}

»Bernecker, W. (1982). Colectividades y revolución social. El anarquismo en la guerra civil española. Barcelona: Crítica.

»Bernecker, W. (2002). "Alemania y España en la época del nacionalsindicalismo", en Vega Cernuda, M.A.-Henning, W. (eds.). España y Alemania. Percepciones mutuas de cinco siglos de historia. Madrid: Editorial Complutense, 155-184.

»Bowen, W.H. (2000). Spaniards and Nazi Germany. Collaboration in the New Order. Missouri: The University of Missouri Press.

»Documents on Foreign German Policy 1918-1945, (DFGP) (1951) Series D, Volume III, London: His Majesty Stationery Office.

"García Pérez, R. (1994). Franquismo y Tercer Reich. Las relaciones económicas hispano-alemanas durante la Segunda Guerra Mundial. Madrid: Centro de Estudios Constitucionales.

» Gliech, O. (2003). "Wilhelm Faupel. Generalstabsoffizier, Militärberater, Präsident des Ibero-Amerikanischen Instituts" en Liehr, R. et al (eds.), (2003). Ein Institut und sein General. Wilhelm Faupel und das IberoAmerikanische Institut in der Zeit des Nationalsozialismus. Frankfurt am Main: Vervuert Verlag, 131-279.

»Gómez Molina, A.-Thomàs, J.M. (2003). Serrano Suñer. Barcelona: Ediciones B.

"Griffin, Roger (1991). The nature of fascism. London: Pinter.

» Janué Miret, M. (2013). “La atracción del falangismo a la causa nacionalsocialista por parte de la Sociedad Germano-Española de Berlín durante la Guerra Civil Española", en Ruiz Carnicer, M.A. (ed.), Falange. Las culturas políticas del fascismo en España (1936-1975). Zaragona: Institución “Fernando El Católico"/CSIC, 240-261.

» Les Archives secrètes de la Wilhemstrasse III: L'Allemagne et la Guerre Civile Espagnole (1936-1939). París: Plon.

»Merkes, M. (1969). Die deutsche Politik gegenüber dem spanischen Bürgerkrieg, 1936-1939. Bonn: Röhrscheid

» Morant i Ariño, T. (2013a). Las relaciones y visitas entre la Sección Femenina de Falange y las organizaciones femeninas nazis, 1936-1945. Tesis Doctoral inédita. València: Universitat de València.

» Morant i Ariño, T. (2013b). “'Todo ha sido como en cine'. El viatge d'un grup d'Auxilio Social a Alemanya, tardor de 1937", en Ruiz Carnicer, M.A. (ed.). Falange. Las culturas políticas del fascismo en España (1936-1975). Zaragona: Institución “Fernando El Católico"/CSIC, 317-334.

» Núñez Seixas, X.M. (2015). "Falangismo, nacionalsocialismo y el mito de Hitler en España (1931-1945). Revista de Estudios Políticos, núm. 169, 13-43.

»Paxton, Robert O. (1995). Anatomía del fascismo. Barcelona: Península.

»Payne, Stanley G. (1995). Historia del fascismo. Barcelona: Planeta. 
»Payne, S.G. (2008). Franco y Hitler. España, Alemania, la Segunda Guerra Mundial y el Holocausto. Madrid: La Esfera de los Libros.

»Ruhl, K.J. (1986). Franco, Falange y Tercer Reich. Madrid: Akal.

"Sáenz-Francés San Baldomero, E. (2006), "Los diarios secretos del embajador von Moltke. Un estudio preliminar", en Letras de Deusto, Volumen 36, 110, 85-134.

"Sáenz-Francés San Baldomero, E. (2009), Entre la antorcha y la esvástica. Franco en la encrucijada de la Segunda Guerra Mundial. Madrid: Actas.

"Saz, I. (1996). "La peculiaritat del feixisme espanyol”. Afers, 25, 624-637.

»Serrano Suñer, R. (1973). Entre Hendaya y Gibraltar. Barcelona: Nauta.

"Thomàs, J.M. (1999). Lo que fue la Falange. La Falange y los falangistas de José Antonio. Hedilla y la Unificación. Franco y el fin de la Falange Española de las JONS. Barcelona: Plaza\&Janés.

»Thomàs, J.M. (2001). La Falange de Franco. Fascismo y fascistización en el régimen franquista (1937-1945). Barcelona: Plaza y Janés.

"Thomàs, J.M. (2016). Franquistas contra franquistas. Luchas por el poder en la cúpula del régimen de Franco. Barcelona: Debate/Penguim Random House.

»Thomàs, J.M. (2017). José Antonio. Realidad y mito. Barcelona: Debate/ Penguim Random House. Edición en lengua inglesa (2019). José Antonio Primo de Rivera. The Reality and Myth of a Spanish Fascist leader. LondonNew York: Beghahn Books.

» Viñas, A. (1977). La Alemania nazi y el 18 de julio. Madrid: Alianza.

»Viñas, A. (1984). Guerra, dinero y dictadura. Ayuda fascista y autarquía en España. Barcelona: Crítica.

»Whealey, R.H. (1989). The Nazi role in the Spanish Civil War. Lexington: The University Press of Kentucky. 